\title{
Changes in muscle coactivation during running: a comparison between two techniques, forefoot vs rearfoot
}

\author{
Daniel Araya, Juan López, Germán Villalobos, Rodrigo Guzmán-Venegas, Oscar Valencia \\ Laboratorio Integrativo de Biomecánica y Fisiología del Esfuerzo, Escuela de Kinesiología, Universidad de los Andes, Chile.
}

doi: $10.18176 /$ archmeddeporte.00059

Received: 30/10/2021 Accepted: 04/06/2021

Key words: Lower limb. Muscle pairs. Running cycle. Surface electromyography.

\section{Summary}

Introduction: Surface electromyography has been a technique used to describe muscle activity during running. However, there is little literature that analyses the behaviour of muscle coactivation in runners, describing the effect between two techniques associated with the initial contact, such as the use of rearfoot (RF) and forefoot (FF).

Material and method: The purpose of this study was to compare muscle coactivation levels developed in the lower limb during two running techniques, FF vs RF. Fourteen amateur runners were evaluated (eight men, six women; age $=23.21 \pm 3.58$ years, mass $=63.89 \pm 8.13 \mathrm{~kg}$, height $=1.68 \pm 0.08 \mathrm{~m}$ ). Surface electromyography was used to measure muscle activity during both running techniques evaluated on a treadmill, considering the muscle pairs: Rectus femoris- Biceps femoris (RFe-BF), Lateral Gastrocnemius-Tibialis Anterior (LG-TA), and Medial Gastrocnemius - Tibialis Anterior (MG-TA). These were calculated in three windows considering ten running cycles (0-5\%, 80-100\%, and 0-100\%). To compare FF vs RF t-student test for paired data was used.

Results: It was observed significant differences in the MG-TA pair ( $F F=18.42 \pm 11.84 \%$ vs RF $=39.05 \pm 13.28 \%, p=0.0018$ during $0-5 \%$, and RFe-BF pair ( $F F=42.38 \pm 18.11 \%$ vs $R F=28.37 \pm 17.2 \%, p=0.0331$ ) during $80-100 \%$ of the race.

Conclusion: Our findings show that the behaviour of muscle coactivation is different between FF vs RF techniques if we analyze little windows in the running cycle. This could be associated with an increase in the joint stability between these short intervals, represented in the initial and final regions of the running cycle.

\section{Cambios en la coactivación muscular durante la carrera: una comparación entre dos técnicas (antepié vs retropié)}

\section{Resumen}

Introducción: La electromiografía de superficie ha sido una técnica usada para describir la actividad muscular durante la carrera. Sin embargo, hay poca literatura que analice el comportamiento de la coactivación muscular en corredores, describiendo el efecto entre dos técnicas asociadas al contacto inial, tal como el uso de retropié y antepié.

Material y método: El propósito de este estudio fue comparar los niveles de coactivación desarrollados en la extremidad inferior, utilizando dos técnicas de carrera, antepié (FF) vs retropié (RF). Catorce corredores amateurs fueron evaluados (8 hombres, 6 mujeres; edad = 23,21 $\pm 3,58$ años, masa $=63,89 \pm 8,13 \mathrm{~kg}$, estatura $=1,68 \pm 0,08 \mathrm{~m}$ ). Se utilizó electromiografía de superficie para medir la actividad muscular al momento de ejecutar ambas técnicas de carrera sobre una trotadora, considerando los siguientes pares musculares: Recto Femoral- Bíceps Femoral (RFe-BF), Gastrocnemio Lateral - Tibial Anterior (LG-TA) y Gastrocnemio Medial - Tibial Anterior (MG-TA). Estos se calcularon en tres ventanas considerando diez ciclos de ejecución (0-5\%, 80-100\% y 0-100\%). Para comparar FF vs RF se utilizó la prueba t-student para datos pareados.

Resultados: Se observan diferencias significativas en el par MG-TA ( $F F=18,42 \pm 11,84 \%$ vs $R F=39,05 \pm 13,28 \%, p=0,0018$ ) durante el $0-5 \%$, y el par RFe-BF ( $F F=42,38 \pm 18,11 \%$ vs $R F=28,37 \pm 17,2 \%, p=0,0331$ ) durante el $80-100 \%$ de la carrera.

Palabras clave: Extremidad inferior. Pares musculares. Ciclo de carrera. Electromiografía de superficie.
Conclusión: Nuestros hallazgos muestran que el comportamiento de la coactivación muscular es diferente entre las técnicas de FFy RF si analizamos pequeñas ventanas en el ciclo de carrera. Esto podría estar asociado con un aumento de la estabilidad articular entre estos cortos intervalos, representados en la región inicial y final del ciclo de carrera. 


\section{Introduction}

The popularity of running has increased over the years, mainly in young people, men and women. This increase has been accompanied by a rise in the number of injuries ${ }^{1}$. Some epidemiological studies indicate that more than $50 \%$ of regular runners report more than one injury annually and that the majority are due to overuse ${ }^{2}$. However, there are a large number of factors associated with an adverse event, including sex, distance travelled, and the type of technique used during initial contact, the latter being a highly associated factor with the rate of injury to lower limbs 3 . One of the first studies linked to the description of running techniques was developed by Laughton et al. ${ }^{4}$. Today, among the techniques used at initial contact, the use of forefoot (FF) and rearfoot (RF) stands out, the latter being the most used by amateur runners ${ }^{5}$. These techniques have been extensively studied, especially the kinematic and kinetic variables ${ }^{1,6,7}$.

Although both techniques involve energy absorption between impact and medium support, their biomechanics are different. The RF technique is associated with laxity of the plantar fascia and structures surrounding the ankle-foot complex, transferring energy to the proximal bone structures (one of which is the tibia) ${ }^{8}$. Furthermore, the FF technique achieves energy absorption through the plantar fascia and eccentric contraction of the lower limb extensors ${ }^{8-10}$. To achieve this, a rigid ankle-foot complex is required, specifically to maintain tension over the plantar fascia. However, there are no studies that describe the muscle activity produced to maintain joint stability.

A study developed by Lieberman et al. (2010), states that the FF technique could reduce the risk of injury due to the low energy absorbed by the knee, generating less acceleration of the tibia and impact on the ground ${ }^{10}$.

Landreneau et al. reported increased activity of the medial gastrocnemius (MG) with FF technique during impact and mid support without kinematic differences in the frontal plane of the ankle. This suggests that runners using the FF technique develop neuromuscular adaptation mechanisms to stabilize the joints in both the sagittal and frontal planes ${ }^{11}$.

A review developed by Latash, affirms that the coactivation of antagonistic muscle pairs could be a neural control mechanism to improve joint stability ${ }^{12}$. However, there is little evidence based on the activity of the lower limb muscles during these running techniques. As stated above, the objective of the research sought to compare the variations in the levels of coactivation in the lower limb when using FF vs RF techniques in amateur runners. Based on the above, we hypothesized that there are differences in the coactivation levels when comparing both running techniques.

\section{Material and method}

Considering a cross-sectional study, fourteen amateur runners were included, with a running frequency equal to or greater than three times a week (5 kilometres each day). These runners were selected considering participation in $10 \mathrm{~km}$ races. Participants with any injury, surgery, or lower limb pain within the six months before the procedure, were excluded. All volunteers signed an informed consent, approved by a local ethics committee in accordance with the Declaration of Helsinki (March 2019; code: CEC201905).

\section{Evaluation protocol}

Regarding the evaluation protocol, we requested all participants who attended to bring their regular training shoe (greater than or equal to one month of use). Initially, anthropometric characteristics of each athlete utilised to biomechanics 3D model and the dominant lower limb (leg used to kick a soccer ball) were evaluated. The kinematic behaviour of the foot during the race was described by two reflective markers located at the base of the second metatarsal and apex of the calcaneus, according to the plugin gait model ${ }^{13}$. These markers determined the moments of the initial contact and take-off of the race, using a 3D analysis system with eight infrared cameras (T- Series; Vicon Motion Systems, Oxford, UK) at a capture frequency of $200 \mathrm{~Hz}$. Simultaneously, the EMG activity of five muscles was recorded in the dominant lower limb of each runner, according to SENIAM recommendation ${ }^{14}$. The evaluated muscles were: tibialis anterior (TA), medial gastrocnemius (MG), lateral gastrocnemius ( $L G)$, rectus femoris (RFe), and biceps femoris (BF). Previously, the areas established for each muscle were shaved and cleaned with 95\% denatured alcohol and cotton. EMG signals were recorded using EMG equipment (Bagnoli-16. Delsys ${ }^{\circledR}$, USA), with a sampling frequency of $1000 \mathrm{~Hz}$. Then, each volunteer developed a five-minute warm-up at a self-selected speed over a treadmill (H/P/Cosmos ${ }^{\circledast}$, Model LE200 CE Germany). Subsequently, each athlete ran for approximately three minutes at a previously determined speed (average of three self-selected speeds under the following indication: "we will adjust the speed of the treadmill as close as possible to your running speed, this should be comfortable for you"). Twenty cycles were recorded at the end of each running technique (FF and RF), the order of which was randomized for each participant. Finally, the maximum voluntary contraction (MVC) of each muscle mentioned above (MG, LG, TA, RFe, and BF) was measured. This allowed normalizing the EMG signals acquired during the race and expressing them as a percentage of the MVC.

\section{Data processing}

The EMG signals were rectified and processed with a fourth-order $20 \mathrm{~Hz}$ low pass filter (Butterworth type) ${ }^{15}$. The EMG amplitude was calculated considering the average of the rectified signals during ten running cycles. Then each muscle was adjusted to its respective MVC (reported as \%MVC). After that, the muscle coactivation was calculated using the formula proposed by Falconer \& Winter ${ }^{16}$.

$$
\frac{\% \text { Coactivation }=(\text { A\&B common area })}{(\text { A area }+ \text { B area })} \times 100
$$

Where $A$ (e.g. activity of the TA) and B (e.g. activity of the MG) represent two antagonistic muscles, considering the common area between them $(A \& B)$ divided by the sum of their areas $(A+B)$, multiplied by 100 With this, the following muscle pairs were determined: rectus femorisbiceps femoris (RFe-BF), lateral gastrocnemius - tibialis anterior (LG-TA), and medial gastrocnemius - tibialis anterior (MG-TA). These coactivation data were calculated in ten central cycles of the race, considering three windows: i.- between 0-5\% running cycle (stance phase), ii.- between 80 100\% running cycle (swing phase), iii.- and the complete cycle (0-100\%) (Figure 1). All data were processed with Python 3.5 (Van Rossum, 2014). 
Figure 1 . Shows three windows where it was calculated the muscle coactivation during the rearfoot technique, using the MG-TA muscle pair. A) 0-100\% running cycle; B) 0-5\% running cycle (initial grey area); and C) $80-100 \%$ running cycle (final grey area). The black area represents the coactivation between both muscles (MG-TA).
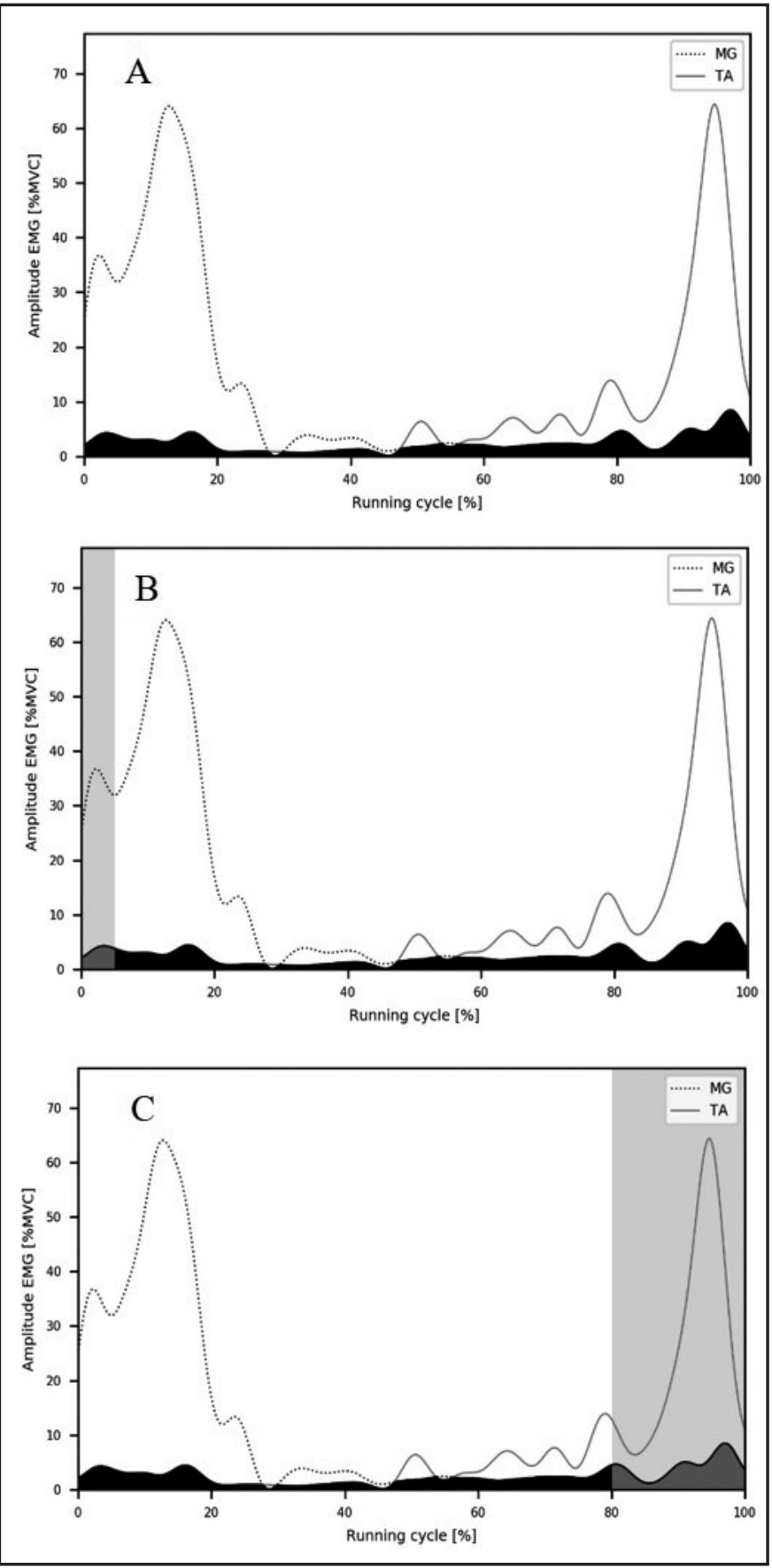

\section{Statistical analysis}

The demographic data of the volunteers was characterized by a descriptive statistic (average and standard deviation). Previously, the normality of the variables (muscle coactivation and amplitude) was evaluated with the Shapiro-Wilk test, considering the data of three windows analyzed (0-5\%, 80-100\%, and 0-100\% of the running cycle). The coactivation data (RFe-BF, LG-TA, and MG-TA muscles pairs) was represented with the average and its standard deviation. To compare between both running techniques (FF vs RF) the t-student test for paired data was used. Additionally, the effect size was calculated, in order to report the magnitudes of the differences founded, considering the Cohen's $d^{18}$ : small $\sim 0.2$, medium $\sim 0.5$, large $\sim 0.8$, and very large $\sim 1.3$. All statistical analyses were carried out at two tails, establishing the differences with a p-value $<0.05$, using the GraphPad Prism software (version 8.4.1, San Diego, California USA).

\section{Results}

Fourteen runners ( 6 women and 8 men) were evaluated; their average running speed was $8.68 \mathrm{~km} / \mathrm{h}$ (Table 1). All reported initial contact with rearfoot as their primary technique.

When comparing the coactivation levels reported by the different muscle pairs between the FF vs RF techniques, significant differences were found in the GM-TA pair (FF $=18.42 \pm 11.84 \%$ vs RF $=39.05 \pm$ $13.28 \%, p=0.0018, d=1.63)$ during $0-5 \%$ at the initial stance phase, and in RFe-BF ( FF $=42.38 \pm 18.11 \%$ vs RF $=28.37 \pm 17.2 \%, p=0.0331$, $d=0.79$ ) during $80-100 \%$ in the swing phase (Table 2). Both muscle pairs describe a large effect, considering Cohen's d. Regarding the LG-TA muscle pair, there were no significant differences between running techniques (Table 2)

\section{Discussion}

The objective of the present investigation was to compare the levels of muscle coactivation in the lower limb during two running techniques (FF vs RF). For this, three windows of analysis were considered. In relation to the aforementioned, the main differences were found in the most small windows (0-5\% and $80-100 \%$ of the running cycle) when it was compared FF vs RF techniques. The first finding reports a greater magnitude of coactivation for the MG-TA pair with the use of RF between $0-5 \%$ of the running cycle. This could be attributed to an increased requirement for ankle stability during the initial impact, offset by an increase in the coactivation of the MG-TA pair during the use of RF. Which could be related to the findings of Kuhman et al., who refers to

Table 1. Demographic characteristics of the evaluated runners (average and standard deviation).

\begin{tabular}{lccc}
\hline & $\begin{array}{c}\text { Men } \\
(\mathbf{n}=\mathbf{8})\end{array}$ & $\begin{array}{c}\text { Women } \\
(\mathbf{n}=6)\end{array}$ & $\begin{array}{c}\text { Total } \\
(\mathbf{n}=\mathbf{1 4})\end{array}$ \\
\hline Age(years) & $22.38(1.60)$ & $24.33(5.2)$ & $23.21(3.58)$ \\
Height $(\mathrm{m})$ & $1.74(0.05)$ & $1.61(0.05)$ & $1.68(0.08)$ \\
Mass $(\mathrm{kg})$ & $69.68(3.64)$ & $56.18(5.36)$ & $63.89(8.13)$ \\
BMI $\left(\mathrm{kg} / \mathrm{m}^{2}\right)$ & $23.15(1.58)$ & $21.63(1.04)$ & $22.5(1.56)$ \\
Speed $(\mathrm{km} / \mathrm{h})$ & $9.46(1.14)$ & $7.63(0.53)$ & $8.68(1.3)$ \\
\hline
\end{tabular}


Table 2 . Comparison between muscle coactivations represented by the average and standard deviation in the rearfoot vs forefoot techniques (considering three windows analysed in relation to the running cycle: [0-100\%], [80-100\%], and [0-5\%]). Significant differences are indicated with a * $p<0.05$. Additionally, the effect size was reported with Cohen's $d$.

\begin{tabular}{|c|c|c|c|c|c|}
\hline & & Rearfoot $(n=14)$ & Forefoot $(n=14)$ & p-value & Cohen's $d$ \\
\hline \multirow[t]{3}{*}{$0-100 \%$} & RFe-BF (\%) & $36.58(11.97)$ & $37.73(12.31)$ & 0.4229 & 0.09 (small) \\
\hline & MG-TA (\%) & $24.71(5.09)$ & $25.11(8.21)$ & 0.8294 & 0.05 (small) \\
\hline & LG-TA (\%) & $24.76(4.18)$ & $25.80(9.52)$ & 0.6624 & 0.12 (small) \\
\hline \multirow[t]{3}{*}{$80-100 \%$} & RFe-BF (\%) & $28.37(17.21)$ & $42.38(18.11)$ & $0.0331 *$ & 0.79 (large) \\
\hline & MG-TA (\%) & $35.55(13.50)$ & $28.08(13.50)$ & 0.1976 & 0.55 (medium) \\
\hline & LG-TA (\%) & $35.98(14.52)$ & $28.68(17.41)$ & 0.3367 & 0.45 (medium) \\
\hline \multirow[t]{3}{*}{$0-5 \%$} & RFe-BF (\%) & $53.96(22.70)$ & $49.54(20.44)$ & 0.5134 & 0.20 (small) \\
\hline & MG-TA (\%) & 39.05 (13.28) & $18.42(11.84)$ & $0.0018^{*}$ & 1.63 (very large) \\
\hline & LG-TA (\%) & $30.28(13.63)$ & $22.89(17.10)$ & 0.1748 & 0.47 (Medium) \\
\hline
\end{tabular}

the need for a higher dorsiflexor torque at impact to control the sudden plantarflexion generated after heel contact ${ }^{7}$. Likewise, another study reflects a greater magnitude of the anterior tibial during the RF technique, this could justify a type of eccentric work of this muscle during the beginning of the support phase, providing greater synchronization with the $\mathrm{MG}^{15}$, also allowing a controlled descent of the forefoot.

The second finding describes a greater coactivation with the use of FF in the RFe-BF pair during $80-100 \%$ of the running cycle. This could be related to the lower excursion of the knee's range of motion with the use of FF compared to the $\mathrm{RF}^{4}$, which would lead to a greater requirement of stability at the hip and knee level, considering that both rectus and biceps femoris are biarticular muscles, responsible for compensating this requirement ${ }^{19}$. Another justification for the second finding is that the literature reports a lower joint contact force in the hip and knee at the moment of the initial impact during the race with the use of FF technique ${ }^{19}$. This could be translated into an energy dissipation strategy associated with the increased coactivation of the RFe-BF pair found in this study. At the same time, the increase of the coactivation during swing phase could also be a consequence of the increased activation of the hamstrings in order to control the extension of the knee, this occurs since in the FF technique, there is a greater degree of flexion in this joint during initial contact, also associated with a shorter stride length ${ }^{5}$.

On the other hand, no significant differences were found in the LG-TA pair. This may be associated with the structure and anatomical disposition of the triceps surae, where the MG represents $30 \%$ of the total volume, considered twice the volume of the LG, together with a more lateral disposition of the $L^{20}$. These characteristics could contribute to a low level of muscle coactivation generated between $L G$ and TA during the race.

Based on the findings of the present study, future research could explore other time windows, such as toe off during the stance phase, because this could show a more specific behaviour of the muscle activation and coactivation, in order to improve our understanding of the lower limb during running. Besides, one attractive alternative could be the analysis of the coactivation of muscular pairs in the frontal plane, considering the frequent kinematics alterations in runners, observed by other studies ${ }^{19}$.

Some limitations observed in this study were: a) the use of a treadmill to simulate the run at comfortable speed by the runners, considering that, normally, the space and its characteristics could not agree with training places or competitions; b) all runners routinely performed the RF technique, experimentally requesting the use of $\mathrm{FF} ; \mathrm{c}$ ) with our current data it is not possible to determine the most appropriate technique for runners, mainly because the differences found are in function of an acute effect between FF vs RF. Therefore, this point could be an interesting topic for a future work.

\section{Conclusion}

According to the evaluated sample, the behaviour of muscle coactivation is different between FF vs RF techniques, considering the temporal window analysis based on the race cycle. Our results show that the FF technique may require pre-activation between antagonist muscles in order to develop possible anticipatory adjustments at the knee and hip levels, allowing better mechanical energy transfer. Also, less ankle coercion would be an adaptation to achieve a mechanical advantage. On the other hand, the RF technique requires greater ankle control to modulate the abrupt fall of the forefoot at the moment of impact, this would be delivered by coactivation between MG-TA.

\section{Acknowledgements}

We would like to thank all the staff members of the "Laboratorio Integrativo de Biomecánica y Fisiología del Esfuerzo".

\section{Conflict of interest}

The author do not declare a conflict of interest. 


\section{Bibliography}

1. Daoud Al, Geissler GJ, Wang F, Saretsky J, Daoud YA, Lieberman DE. Foot strike and injury rates in endurance runners: a retrospective study. Med Sci Sports Exerc. 2012;44:1325-34.

2. Tschopp M, Brunner F. Erkrankungen und Überlastungsschäden an der unteren Extremität bei Langstreckenläufern. Z Rheumatol. 2017;76:443-50.

3. Hespanhol Junior LC, Pena Costa LO, Lopes AD. Previous injuries and some training characteristics predict running-related injuries in recreational runners: a prospective cohort study. J Physiother. 2013;59:263-9.

4. Laughton CA, Davis IM, Hamill J. Effect of strike pattern and orthotic intervention on tibial shock during running. J App/ Biomech. 2003;19:153-68.

5. Almeida MO, Davis IS, Lopes AD. Biomechanical differences of foot-strike patterns during running: A systematic review with meta-analysis. J Orthop Sport Phys Ther. 2015;45:738-55.

6. KernozekTW, Knaus A, RademakerT, AlmonroederTG. The effects of habitual foot strike patterns on Achilles tendon loading in female runners. Gait Posture. 2018;66:283-7.

7. Kuhman D, Melcher D, Paquette MR. Ankle and knee kinetics between strike patterns at common training speeds in competitive male runners. Eur J Sport Sci. 2016;16:433-40.

8. Williams DSB, Green DH, Wurzinger B. Changes in lower extremity movement and power absorption during forefoot striking and barefoot running. Int J Sports Phys Ther. 2012;7:525-32.

9. Arendse RE, Noakes TD, Azevedo LB, Romanov N, Schwellnus MP, Fletcher G. Reduced eccentric loading of the knee with the pose running method. Med Sci Sports Exerc 2004;36:272-7.
10. Lieberman DE, Venkadesan M, Werbel WA, Daoud Al, D'Andrea S, Davis IS, et al. Foot strike patterns and collision forces in habitually barefoot versus shod runners. Nature. 2010;463:531-535

11. Landreneau LL, Watts K, Heitzman JE, Childers WL. Lower limb muscle activity during forefoot and rearfoot strike running techniques. Int J Sports Phys Ther. 2014;9:888-897.

12. Latash ML. Muscle coactivation: definitions, mechanisms, and functions. J Neurophysiol. 2018;120:88-104

13. Kadaba MP, Ramakrishnan HK, Wootten ME. Measurement of lower extremity kinematics during level walking. J Orthop Res. 1990;8:383-92.

14. Hermens HJ, Freriks B, Disselhorst-Klug C, Rau G. Development of recommendations for SEMG sensors and sensor placement procedures. J Electromyogr Kinesiol. 2000;10:361-74

15. Valencia O, Cristi I, Ahumada D, Meza K, Salas R, Weinstein A, et al. The initial impact with forefoot increases the muscular activity of gastrocnemius during running. A quantitative study of electromyographic activity. Retos. 2020;38:271-5.

16. Falconer K, Winter DA. Quantitative assessment of co-contraction at the ankle joint in walking. Electromyogr Clin Neurophysiol. 1985;25:135-49.

17. Van Rossum G. The Python library. Python software foundation. 2014

18. Ferguson CJ. An effect size primer: A guide for clinicians and researchers. Prof Psychol Res Pract. 2009;40:532-8.

19. Rooney BD, Derrick TR. Joint contact loading in forefoot and rearfoot strike patterns during running. J Biomech. 2013;46:2201-6.

20. Bojsen-Møller J, Magnusson SP. Heterogeneous loading of the human achilles tendon in vivo. Exerc Sport Sci Rev. 2015;43:190-7. 